\title{
1) Title: The role of pain-related anxiety in adolescents' disability, and social impairment: ALSPAC data
}

2) Running title: Pain-related anxiety, disability, and social impairment

3) Author's names: Caes $\mathrm{L}^{1}$, Fisher $\mathrm{E}^{2}$, Clinch $\mathrm{J}^{3}$, Tobias $\mathrm{JH}^{4}$, Eccleston $\mathrm{C}^{2}$

4) Auhtor's institutons:

${ }^{1}$ Centre for Pediatric Pain Research, IWK Health Centre, Canada

${ }^{2}$ Centre for Pain Research, The University of Bath, UK

${ }^{3}$ Bristol Royal Children's Hospital, University of Bristol and The Royal National Hospital for Rheumatic Diseases, Bath.

${ }^{4}$ Musculoskeletal Research Unit, School of Clinical Sciences, University of Bristol

5) Corresponding author: Dr. Line Caes; Centre for Pediatric Pain Research, IWK Health Centre, 5850/5980 University Avenue, Halifax, NS, B3K 6R8, Canada; Email: line.caes@iwk.nshealth.ca; Tel: +1 (902) 470 - 6759; Fax: +1 (902) 470 - 7118

6) Article category: Original article

7) Funding statement: Dr. Line Caes is a postdoctoral fellow funded by the Louise \& Alan Edwards Post-Doctoral Fellowship in Pediatric Pain Research. Dr. Line Caes was awarded The Southwood Adolescent Chronic Pain Visiting Award enabling her to visit the Centre for Pain Research at The University of Bath, UK in December 2012. This study was designed and initiated during her visit. Emma Fisher is a PhD student funded by The University of Bath Graduate School Award. Pain in Child Health (PiCH) funded Emma Fisher's visit in 
February 2013 to the Centre for Pediatric Pain Research at the IWK Health Centre, Nova Scotia, Halifax, Canada, which was intended to complete all aspects of this study.

8) Conflicts of interest: There are no conflicts of interest that may arise as a result of the research presented in this article.

9) What is already known about this topic?

- The fear-avoidance model explains the role of anxiety in maintaining pain-avoidance behaviour and disability.

- Although social functioning is of major importance for adolescents it is not incorporated within the fear-avoidance model.

What does this study add?

- High levels of pain-related anxiety are associated with more disability in communitydwelling adolescents reporting recurrent pain.

- Pain-related anxiety has a role in explaining perceived social impairment in girls with recurrent pain. 


\section{Abstract}

Background: Anxiety, in particular pain-related anxiety, plays an important role in explaining the severity of pain complaints and pain-related disability in both adults and children with chronic pain. The Fear-Avoidance Model (FAM) describes how pain-related anxiety plays a critical role in the maintenance of pain-avoidance behaviour, which in turn influences painrelated disability. However, the FAM does not take into account broader aspects of adolescence, such as social functioning, which could be negatively impacted by anxiety. In addition, most studies examining the role of anxiety in pain have used small convenience or clinical samples. By using a large UK epidemiological database, this study investigated the associations between pain-related anxiety, disability and judgements of social impairment. Methods: Participants $(N=856)$ with recurrent pain were selected from a larger epidemiological study (Avon Longitudinal Study of Parents and Children, ALSPAC) of adolescents attending a research clinic at the age of $17(N=5170)$. Adolescents completed a self-report questionnaire on pain-related anxiety, disability, and perceived social impairment. Results: High levels of pain-related anxiety were associated with more disability. In girls, higher levels of pain-related anxiety were also related to the self-perception of greater impairment in social functioning compared to their peers. Conclusions: Pain-related anxiety was associated with greater pain-related disability and impaired social functioning. Social functioning should be explored as an integral part of fear-avoidance models of adolescent chronic pain. 


\section{Introduction}

Pain is a common experience during adolescence, developmentally normal, and for most adolescents pain is short in duration and does not interrupt daily functioning. However, pain can persist for longer than three months (King et al., 2011), become disabling and distressing (Gauntlet-Gilbert \& Eccleston, 2007; Logan \& Scharff, 2005; Logan et al., 2008), and lead to emotional problems, such as depression, anxiety, and lowered self-esteem (Eccleston et al., 2004; Peterson \& Palermo, 2004; Varni et al., 1996).

Anxiety variables have been found to influence the severity of pain complaints and pain-related disability in paediatric chronic pain patients (Cohen et al., 2010; Simons et al., 2012). Compared to a community sample, those with a clinical anxiety disorder report elevated pain-related anxiety and disability (Carleton et al., 2009). The Fear-Avoidance Model (FAM, Vlaeyen \& Linton, 2000) has been used to interpret findings because it provides useful explanations of how anxiety can maintain avoidance behaviour for both adult and paediatric samples (Crombez et al. 2012; Simons \& Kaczynski, 2012). The FAM postulates that a catastrophic interpretation of pain is a precursor for pain-related fear and pain-avoidance tendencies, which in turn result in poor functioning (Leeuw et al. 2007; Vlaeyen \& Linton, 2000).

Although the FAM is useful in explaining avoidance behaviour, it has yet to be extended into broader areas of the adolescent experience, such as social functioning. Social, psychological, and physical maturation are important aspects of an adolescent's development (Steinberg \& Morris, 2001), upon which anxiety can have deleterious effects. Highly anxious adolescents tend to perceive themselves as less competent relative to non-anxious adolescents in their social and physical functioning (Chansky \& Kendall, 1997; Ekornås et al., 2010; La Greca \& Lopez, 1998; Lewinsohn et al., 1998). In a study investigating self-perception of social functioning, adolescents with chronic pain judged themselves to be more delayed on 
many important domains of their social functioning, including school progress, peer relationships, and independence. Furthermore, increased anxiety has been associated with adolescents judging themselves to be less independent compared to peers (Eccleston et al., 2008). However, to our knowledge no other study has investigated the association between pain-related anxiety and social functioning in adolescents with chronic or recurrent pain.

To date, studies examining emotional variables, such as anxiety in pain have made use of small convenience, opportunity, or clinical samples. Large epidemiological studies have traditionally paid little attention to emotional variables (Eccleston, 2008). The Avon Longitudinal Study of Parents and Children (ALSPAC) is a longitudinal population-based cohort study, which investigates a wide range of health outcomes, including pain, presenting an ideal opportunity to investigate the relationship between pain-related anxiety, disability, and judgements of social impairment. We hypothesised that high levels of pain-related anxiety in adolescents are positively associated with disability and with the belief that one is more socially impaired in comparison to peers. As daily and social impairment of adolescents can be influenced by their social environment (McElhaney, \& Allen, 2001), we controlled for parental social status.

\section{Methods}

\subsection{Study population}

Data were taken from ALSPAC, a longitudinal population-based cohort study following children born between April 1991 and December 1992 (see www.alspac.bris.ac.uk for more information, which also contains details of all the data available through a fully searchable data dictionary: http://www.bris.ac.uk/alspac/researchers/data-access/datadictionary/). A total of 14,541 pregnancies were enrolled, with 13,988 children surviving at 12 months. The current study is based on self-reported data from adolescents who returned a questionnaire inquiring about pain, pain-related anxiety, disability and social impairment 
after being invited to attend a university research clinic at 17 years of age $\left(N_{\text {attending }}=5170\right.$; response rate $=76.86 \%$ ). At this annual visit to the university research clinic participants were invited to complete several health assessments. Biological samples and physiological, anthropometric, and psychological measures were collected. All participants who attended the research clinic at 17 years of age received a questionnaire about pain and were requested to complete it during the clinic visit, or to return it by post. A total of 3974 adolescents (1651 boys $(41.5 \%)$ and 2323 girls $\left.(58.5 \%), M_{\text {age }}=17.80, S D_{\text {age }}=.44\right)$ completed the questionnaire, of whom 844 adolescents reported recurrent pain (291 boys (34.5\%) and 553 girls $(65.5 \%)$; $M_{\text {age }}=17.78, S D_{\text {age }}=.42$ ). The sub-sample of adolescents reporting recurrent pain will be the sample used in this study (see Figure 1 for an overview of the recruitment process). Ethical approval was obtained from the ALSPAC Law and Ethics Committee and the Local Research Ethics Committees. Adolescent consent was obtained.

- Insert Figure 1 about here -

\subsection{Materials and Methods}

\subsubsection{Adolescents' pain and disability}

Pain complaints and disability were assessed by means of a structured pain questionnaire created for this particular study. The pain questionnaire was composed of scales and domains from questionnaires previously validated in UK populations, such as the von Korff Graded Chronic Pain Scale (Huguet \& Miro, 2008; Von Korff et al., 1992). First, adolescents were asked whether they had any aches or pains lasting for one day or longer in the past month, and if so, whether these started within the last three months, or more than three months ago (Mallen et al., 2006). Second, adolescents were asked to indicate, using a manikin with front and back view, the exact location of pain(s). Third, adolescents reported their pain intensity in the past six months by means of the following question: "In the past 6 months, on average, how intense was your pain rated on a 1 - 10 scale, where 1 is "no pain" 
and 10 is "pain as bad as could be"?". Fourth, adolescents indicated how many days they were unable to perform their usual activities due to pain (0-6 days; 7-14 days, 15-30 days or 31 days or more). Finally, adolescents indicated on a scale of 1 to 10 how much their pain had interfered with their daily activities in the last six months (ranging from $1=$ no interference to $10=$ unable to carry on activities), and whether their pain had altered their ability to take part in recreational, social, and family activities in the last six months (ranging from $1=$ no change to $10=$ extreme change). A mean score of these two latter items, ranging from 1 to 10 , was calculated to reflect the overall level of interference due to pain in a single score. The Cronbach's alpha of these two combined items was .82, indicating a good internal consistency.

\subsubsection{Pain-related anxiety}

Adolescents completed the Pain Specific Anxiety subscale of the Bath Adolescent Pain Questionnaire (BAPQ; Eccleston et al., 2005). All subscales of the BAPQ have shown a good internal consistency $(.80-.88)$, temporal stability, and construct validity in outpatient chronic pain and rheumatology samples (Eccleston et al., 2005). The Pain Specific Anxiety subscale consists of seven items regarding specific worries or concerns about pain (e.g., I worry about my pain problem, I am afraid to move due to pain, when I think about my pain, it makes me upset). Adolescents reported how often they encounter these worries or concerns (from $0=$ 'Never' to $4=$ 'Always') in the last three to six months. The scores on these seven items are summed to create a total score for Pain Specific Anxiety ranging from 0 to 28 with higher scores indicating more pain-related anxiety. The internal consistency in our sample was $\operatorname{good}(\alpha=.87)$.

\subsubsection{Social impairment}

The adolescents' perception of their social impairment in the last three to six months was measured by the Self-Perception of Development subscale of the BAPQ (Eccleston et al., 
2005). The Self-Perception of Development subscale consists of 11 items covering important domains in the development of adolescents with chronic or recurrent pain, such as emotional adjustment (e.g., How I deal with problems), identity formation (e.g., My plans for the future), and independence (e.g., How often I do things without my parents around). Adolescents are instructed to 'read each statement carefully and think of each one in relation to other people of your age'. Answers range from 0-4 $(0=$ 'Very behind' to $4=$ 'Very ahead'). A total score for self-perception of social impairment is derived by reverse-scoring all items and summing the reversed item scores. The total score ranges from 0 to 44 with higher scores indicating that adolescents perceive themselves as being more socially impaired compared to their peers. The internal consistency in our sample was good $(\alpha=.87)$.

\subsubsection{Parental social status}

Maternal and paternal social status was calculated based on their occupations by using the SOC1990 (Standard Occupational Classifications; Office of Population Censuses and Surveys, 1990). The SOC1990 differentiates four social statuses or skill levels. Each level is defined by taking into account the duration of training and/or work experience required to perform the activities related to the occupation in a competent and efficient way. Higher skill or social level reflects a higher level of required education and /or work-related training or experience. The levels range from one to four; level one refers to occupations that require competence associated with general education (e.g., cleaners and postal workers), whilst level four refers to occupations that require a degree or an equivalent period of relevant work experience (e.g., managers and health professionals) (Office of Population Censuses and Surveys, 1990).

\subsection{Data-analysis}

All hypotheses were investigated in the subsample of adolescents reporting recurrent pain (i.e., adolescents reporting pain in the last month which started more than three months 
ago) at 17 years of age. The association between pain-related anxiety and 1) the level of disability (i.e., interference in daily activities due to pain and number of days unable to perform their usual activities) and 2) self-reported social impairment, were investigated by means of hierarchical linear regression analyses. Adolescent's sex, pain intensity and parental social status were entered in the first level, adolescent's level of pain-related anxiety in the second level. Furthermore, similar hierarchical linear regression analyses were performed separately for boys versus girls to investigate possible sex differences in the associations. SPSS statistical software, version 21.0 (SPSS Inc., Chicago, IL) was used to perform all analyses.

\section{Results}

\subsection{Descriptive data}

Of the 3974 adolescents who completed the questionnaire, 1824 adolescents reported an experience of pain in the past month (45.90\%). For 844 adolescents, this pain started more than three months ago, (defined as recurrent pain; RP; 46.3\%), compared to 965 adolescents who reported that the pain started less than three months ago (defined as recent or new pain; NP; 396 males; 569 females). Results indicated a higher prevalence of recurrent pain in girls $(N=553)$ compared to boys $(N=291)$. Compared to boys, girls also reported significantly higher levels of pain-related anxiety $\left(t(836)=-7.15 ; p<.0001 ; M_{\text {girls }}=7.04 ; S D_{\text {girls }}=5.52\right.$; $\left.M_{\text {boys }}=4.39 ; S D_{\text {boys }}=4.16\right)$.

\subsubsection{Descriptive data for recurrent pain sample}

Table 1 reports the mean scores for pain-related anxiety, disability and social impairment for adolescents reporting recurrent pain. Compared to adolescents reporting recent or new pain (i.e., pain started less than 3 months ago), adolescents experiencing recurrent pain reported significantly more 1$)$ pain-related anxiety $(t(1808)=-8.23, p<.001$, $\left.M_{N P}=4.27, S D_{N P}=4.31\right)$ and 2) interference due to pain $\left(t(1775)=-6.63, p<.001, M_{N P}=\right.$ 
2.70, $\left.S D_{N P}=1.93\right)$. Adolescents with recurrent pain also reported significantly higher pain intensity $\left(t(1792)=-8.49, p<.001, M_{N P}=4.04, S D_{N P}=2.11\right)$. No significant difference was found in the level of perceived social impairment $\left(t(1807)=1.76, p=.08, M_{R P}=16.96, S D_{R P}\right.$ $\left.=6.50, M_{N P}=17.49, S D_{N P}=6.41\right)$ between the recurrent and new pain sample.

Table 1 also presents the means, standard deviations, and ranges of all variables for males versus females within the sample of adolescents reporting recurrent pain. Independent sample t-tests indicated that for all variables girls reported increased pain intensity $(t(830)=$ $6.11, p<.001)$, pain-related anxiety $(t(734)=7.80, p<.001)$, interference due to pain $(t(827)$ $=3.64, p<.001)$, and social impairment $(t(834)=4.42, p<.001)$ compared to boys.

Table 2 reports the percentages of the sample with recurrent pain unable to perform their usual activities over four different durations. A greater proportion of adolescents with recurrent pain reported that they were unable to perform their usual activities for more than 15 days compared to adolescents reporting a new pain experience $\left(3.0 \% ; \chi^{2}(2)=36.02, p<\right.$ $.001)$.

- Insert Tables 1 and 2 about here -

An overview of the pain locations indicated by the adolescents who reported recurrent pain can be found in figure 2 . The most common pain location reported was back or spine pain $(N=467,55.3 \%)$, followed by pain in the calf, ankle or foot $(N=296,35.1 \%)$, knee pain $(N=274,32.5 \%)$ and shoulder pain $(N=242,28.7 \%)$. The number of pain locations per adolescent ranged from 1 to 11 , with the majority of the adolescents reporting pain in two or more locations $(N=611,72.4 \%)$. Adolescents most commonly reported experiencing pain in two locations $(N=227,26.9 \%)$.

- Insert Figure 2 about here -

\subsection{Correlations}


Correlation analyses in the subsample of adolescents reporting recurrent pain indicated that pain-related anxiety was positively correlated with social impairment $\left(r_{(826)}=\right.$ $.13, p<.01)$ and interference due to pain $\left(r_{(824)}=.53, p<.01\right)$. Furthermore, the level of perceived social impairment was significantly correlated with paternal social status $\left(r_{(693)}=-\right.$ $.09, p<.05)$, indicating that a higher level of paternal social status was associated with perceiving themselves less socially impaired compared to their peers. There were no significant correlations found with maternal social status and adolescents' age (all $r_{(649-842)}<$ $.05, n s)$

\subsection{The association between pain-related anxiety and disability}

Hierarchical linear regression analysis, conducted in the subsample of adolescents reporting recurrent pain $^{1}$ revealed a significant positive contribution $(p<.001)$ of both painrelated anxiety and average pain intensity, respectively explaining $13.8 \%$ and $25.1 \%$ of the variance in the level of interference. Similar results were found for the number of days adolescents were unable to perform their usual activities, with pain-related anxiety explaining $7.5 \%$ variance $(p<.001)$ and pain intensity 9.8\% $(p<.001)$. These results indicate that adolescents with higher levels of pain-related anxiety or pain intensity reported higher interference of daily activities, more change in the ability to take part in activities and a larger number of days in which adolescents are unable to perform their usual activities (see Table 3). Hierarchical linear regression analyses performed for boys versus girls separately revealed similar results for both sexes: pain-related anxiety and pain intensity both showed a significant positive contribution $(p<.001 ; p<.01$ respectively) in explaining the level of

\footnotetext{
${ }^{1}$ An alternative question to assess chronic or recurrent pain within the questionnaire asked adolescents over what period adolescents experienced the most troublesome pain (less than 7 days, 1-4 weeks, 1-3 months, over 3 months). Based on this question, 283 adolescents reported troublesome pain experienced over three months. The analyses using this sample of adolescents with troublesome chronic or recurrent pain revealed similar results as the selected sample for our analyses. However, we decided to use the sample of 844 adolescents reporting recurrent pain without taking into account how troublesome the pain is, as we wanted our sample to represent a general population of adolescents with recurrent pain and not only pre-selected adolescents who are troubled by their experience of pain.
} 
variance in pain-related interference and the number of days adolescents were unable to perform their daily activities (see Table $4 \& 5$ for more details).

- Insert Table 2 about here -

3.4 The association between pain-related anxiety and social impairment

Results of a hierarchical linear regression showed that adolescents' level of painrelated anxiety was related to their self-perceived social impairment $(p<.001)$. However, pain-related anxiety only explained $2.5 \%$ of the variance. This finding indicates that adolescents reporting high levels of pain-related anxiety perceive themselves, in comparison to their peers, as more impaired in their social functioning. Adolescents' sex and average pain intensity also contributed significantly $(p<.001)$ in explaining perceived social impairment. Together both variables explained $4.7 \%$ variance in perceived social impairment (see Table 3). Adolescents with higher levels of pain intensity perceive themselves as more impaired than adolescents who report lower levels of pain intensity. Additional hierarchical linear regression analyses performed separately for boys versus girls revealed that pain-related anxiety and pain intensity only showed a association with social impairment in girls, respectively explaining $4.5 \%(p<.001)$ and $1.1 \%$ of variance $(p<.01)$ in perceived social impairment (see Table 5). No associations were found for boys (all $t<1.79$, $n s$, see Table 4).

- Insert Tables 4 \& 5 about here -

\section{Discussion}

For adolescents reporting recurrent pain, pain-related anxiety was positively associated with their disability (i.e., reported interference due to pain in daily activities and the number of days unable to perform daily activities). Second, adolescents experiencing recurrent pain who reported high levels of pain-related anxiety perceived themselves as more socially impaired compared to their peers. However, separate analyses for boys versus girls 
revealed that the association between pain-related anxiety and perceived social impairments was only significant for girls.

Of further interest, in line with previous research (King et al., 2011), half of our sample reported an experience of pain in the past six months and about half of those (i.e., a quarter of the entire sample) experienced recurrent pain. The most common pain locations in the sample of adolescents with recurrent pain were back or spine, lower leg and foot, then knee and shoulder. The majority of adolescents with recurrent pain also reported pain in multiple locations. Unsurprisingly, adolescents with recurrent pain reported higher levels of painrelated anxiety and were more disabled by their pain compared to adolescents experiencing recent pain episodes. Furthermore, higher levels of pain intensity were associated with less preferable outcomes (i.e., higher levels of pain-related anxiety, disability and perceived social impairment). The sample of adolescents experiencing recurrent pain was comprised of almost twice as many girls than boys. Moreover, girls with recurrent pain reported more pain intensity, pain-related anxiety and disability, and perceived themselves as more impaired in their social functioning, compared to adolescent boys with recurrent pain (Huguet \& Miro, 2008; King et al., 2011; Lewinsohn et al., 1997).

To the best of our knowledge, this is the first study investigating the role of painrelated anxiety in explaining pain-related disability, (i.e., one of the main propositions of the fear-avoidance model) within a large community-based sample of adolescents. In accordance with recent findings by Simons \& Kaczynski (2012), who investigated the FAM in highly disabled paediatric chronic pain patients, our results further attest to the applicability of the fear-avoidance model in a large paediatric population cohort. Specifically, the results indicate that pain-related anxiety not only contributes independently to disability in highly disabled adolescents, but can also account for various levels of disability found in community samples who are not seeking medical attention for their pain. The FAM was originally developed to 
explain the development and maintenance of chronic musculoskeletal pain, in particular back pain in adults (Leeuw et al., 2007; Vlaeyen \& Linton, 2000) and has recently been shown to be functional in understanding the level of disability in various paediatric pain samples (e.g., Simons \& Kaczynski, 2012 and Cook, Brawer, Vowles, 2006). Furthermore, as most adolescents in this sample experienced pain in multiple locations, our findings provide support for the generalisation of the role of pain-related anxiety within a variety of pain conditions, including widespread pain. It is worth noting that the pattern of primary pain complaints differs in this sample from other community epidemiology studies. Our sample appears to under-represent headache and over-represent musculoskeletal pain. This variability between studies is not unusual and is probably due to method variance (King et al., 2011). Nonetheless, it will be important to test for replication of these findings in specific pain populations.

Additionally, although the results are preliminary and replication is important, our findings suggest that pain-related anxiety may also play a role in the adolescent's perceived social impairment. However, caution is needed when interpreting this finding as pain-related anxiety only explained a small percentage of the variance and this association was only prevalent in the subsample of girls. Adolescence is a period of childhood characterised by rapid social, psychological and physical maturation in which peers and social networks play a crucial role. Previous research has indicated that challenges, such as the experience of chronic or recurrent pain, can hamper this development by critically changing the social environment of adolescents (e.g., increased social isolation due to lower capability of participating in school, social and leisure activities; Eccleston et al., 2008; Gauntlett-Gilbert \& Eccleston, 2007; Logan et al., 2008). In line with the FAM, our results suggest that this might be particularly the case for adolescents who are highly anxious with regard to their pain experience. Previous findings indicate that adolescent girls, compared to boys, tend to 
worry more about having dyadic friendships, peer evaluation and social approval (Rose \& Rudolph, 2006), which might explain why the association between pain-related anxiety and perceived social impairment is particularly prevalent in girls. As social functioning is an important aspect of adolescents' development, recognition of the role of pain-related anxiety on developmental processes might be a crucial extension when applying the fear-avoidance model to adolescents.

The treatment of pain-related anxiety may be more important than first thought. Specifically, pain-related anxiety plays an independent role in explaining the level of disability and, particularly for girls, social impairment perceived by the adolescent. Focusing only on reduction of adolescent pain intensity might not be sufficient to improve function (Simons et al., 2012). Furthermore, adolescents with higher levels of both pain severity and maladaptive psychological characteristics, such as negative affect and catastrophic thinking, are at risk of persistent pain and disability throughout adulthood (Walker et al., 2012). The early detection of pain-related anxiety and early intervention of anxiety are likely to improve immediate pain-related outcomes and may be potentially protective of longer-term outcomes.

This study is limited to an investigation of associations in this large cohort. Although a large community-based sample has the advantage of more accurately representing the target population, caution needs to be taken when interpreting significant findings. Our effect sizes are moderate to small, in particular with respect to explaining social impairment, thereby potentially limiting the clinical significance of the results and indicating that other factors are likely to play a role in how adolescents perceive their social functioning (e.g., depression; Eccleston et al., 2008, attachment; Bohlin et al., 2000, family environment; O'Brien et al., 2006, and peer relations; Kashikar-Zuck et al., 2007). In addition, a previous article using the clinic data at 17 of the ALSPAC study showed that obesity was associated with severe musculoskeletal pain (Deere et al., 2012), highlighting the importance of obesity in 
explaining the level of pain-related disability. Furthermore, the overall reported level of painrelated anxiety was low and our sample consisted predominantly of girls of 17-18 years of age. Second, the associations are based on cross-sectional data only, because there were no earlier measures on these concepts included in ALSPAC. Therefore the data do not allow us to make any conclusion regarding causality, for which a longitudinal approach is required. Third, no data on adolescent's objective social impairment were available. Although adolescents' perceived pain-related social impairment might have crucial implications on their functioning, future research is needed to investigate and replicate our findings with other measures of development, such as educational attainment, social competence, social emotional development, etc. Finally, although our sample was drawn from a community population and not from a clinic population, we did not ask the adolescents whether they were currently seeking medical attention for their pain and therefore cannot be sure whether or not they were enrolled in treatment.

In conclusion, in accordance with the assumptions of the fear-avoidance model, this large cohort study of adolescents with recurrent pain revealed that pain-related anxiety is important in understanding the level of disability. Moreover, the findings suggest that for girls, painrelated anxiety is also important in explaining judgments these adolescents make about their social functioning compared to their peers.

\section{Acknowledgements}

We are extremely grateful to all the families who took part in this study, the midwives for their help in recruiting them, and the whole ALSPAC team, which includes interviewers, computer and laboratory technicians, clerical workers, research scientists, volunteers, managers, receptionists and nurses. This publication is the work of the authors and they will serve as guarantors for the contents of this paper.

\section{Author Contributions}


All authors discussed the results and commented on the manuscript. Specifically, Dr. Line Caes, first author, took the lead in formulation the hypotheses, performing the analyses and drafting the manuscript. Emma Fisher contributed to the formulation of the hypotheses and performing the analyses and discussing the results. She also provided considerable feedback on the manuscript. Dr. Jacqui Clinch and Dr. Jonathan Tobias were involved by discussing the results and providing considerable feedback on the manuscript. Dr. Christopher Eccleston was involved with the formulation of the hypotheses, discussing the results and providing considerable feedback and comments on the manuscript. 


\section{References}

Bohlin, G., Hagekull, B., Rydell, A.M. (2000). Attachment and social functioning: a longitudinal study from infancy to middle childhood. Soc Dev 9,24-39.

Carleton, R.N., Abrams, M.P., Asmundson, G.H.G., Antony, M.M., McCabe, R.E. (2009). Pain-related anxiety and anxiety sensitivity across anxiety and depressive disorders. $J$ Anxiety Disord 23,791-798.

Chansky, T.E., Kendall, P.C. (1997). Social Expectancies and Self-Perceptions in AnxietyDisordered Children. J Anxiety Disord 11,347-363.

Cohen, L.L., Vowles, K.E., Eccleston, E. (2010). The Impact of Adolescent Chronic Pain on Functioning: Disentangling the Complex Role of Anxiety. J Pain 11,1039-1046.

Cook, A.J., Brawer, P.A., Vowles, K.E. (2006). The fear-avoidance model of chronic pain: validation and age analysis using structural equation modeling. Pain 121:195-206.

Crombez, G., Eccleston, E., Van Damme, S., Vlaeyen, J., Karoly, P. (2012). The fearavoidance model of chronic pain: the next generation. Clin J Pain 28,475-483.

Deere, K.C., Clinch, J., Holliday, K., McBeth J., Crawley, E.M., Sayers, A., Palmer, S., Doerner, R., Clark, E.M., Tobias, J.H. (2012). Obesity is a risk factor for musculoskeletal pain in adolescents: Findings from a population-based cohort. Pain 153,1932-1938.

Eccleston, C. (2008). Children with chronic widespread pain: hunting the snark (Editorial). Pain 138:477-478.

Eccleston, C., Crombez, G., Scotford, A., Clinch, J., Connell, H. (2004). Adolescent chronic pain: patterns and predictors of emotional distress in adolescents with chronic pain and their parents. Pain 108,221-229.

Eccleston, C., Jordan, A., McCracken, L.M., Sleed, M., Connell, H., Clinch, J. (2005). The Bath Adolescent Pain Questionnaire (BAPQ): Development and preliminary psychometric 
evaluation of an instrument to assess the impact of chronic pain on adolescents. Pain 11,263270.

Eccleston, C., Wastell, S., Crombez, G., Jordan, A. (2008). Adolescent social development and chronic pain. Eur J Pain 12,765-774.

Ekornås, B., Lundervold, A.J., Tjus, T., Heimann, M. (2010). Anxiety disorders in 8-11year-old children: Motor skill performance and self-perception of competence. Scand $J$ Psychol 51,217-277.

Gauntlett-Gilbert, J., Eccleston, C. (2007). Disability in adolescents with chronic pain:

Patterns and predictors across different domains of functioning. Pain 131,132-141.

Huguet, A., Miro, J. (2008). The severity of chronic pediatric pain: an epidemiological study. The J Pain 9,226-236.

Kashikar-Zuck, S., Lynch, A.M, Graham, T.B., Swain, N.F., Mullen, S.M., Noll, R.B. (2007). Social functioning and peer relationships of adolescents with juvenile fibromyalgia syndrome. Arthrit Care Res 57,474-480.

King, S., Chambers, C.T., Huguet, A., MacNevin, R.C., McGrath, P.J., Parker, L., MacDonald, A.J. (2011). The epidemiology of chronic pain in children and adolescents revisited: A systematic review. Pain 152,2729-2738.

La Greca, A.M., Lopez, N. (1998). Social anxiety among adolescents: linkages with peer relations and friendships. J Abnormal Psychol 16,83-94.

Leeuw, M., Goossens, M.E.J.B., Linton, S.J., Crombez, G., Boersma, K., Vlaeyen, J. (2007). The fear-avoidance model of musculoskeletal pain: current state of scientific evidence. $J$ Behav Med 30,77-94.

Lewinsohn, P.M., Gotlib, I.H., Lewinsohn, M., Seeley, J.R., Allen, N.B. (1998). Gender differences in anxiety disorders and anxiety symptoms in adolescents. J Abnormal Psychol 107,109-117. 
Lewinsohn, P.M., Zinbarg, R., Seeley, J.R., Lewinsohn, M., Sack, W.H. (1997). Lifetime comorbidity among anxiety disorders and between anxiety disorders and other mental disorders in Adolescents. J Anxiety Disord 11,377-397.

Logan, D.E., Scharff, L. (2005). Relationships between family and parent characteristics and functional abilities in children with recurrent pain syndromes: an investigation of moderating effects on the pathway from pain to disability. J PediatrPsychol 30,698-707.

Logan, D.E., Simons, L.E., Stein, M.J., Chastain, L. (2008). School impairment in adolescents with chronic pain. J Pain 9,407-416.

Mallen, C.D., Peat, G., Thomas, E., Croft, P.R. (2006). Is chronic musculoskeletal pain in adulthood related to factors at birth? A population-based case-control study of young adults. Eur J Epidemiol 2,237-43.

McElhaney, K.B., Allen, J.P. (2001). Autonomy and adolescent social functioning: the moderating effect of risk. Child Dev 72,220-235.

O'Brien, M.P., Gordon, J.L., Bearden, C.E., Lopez, S.R., Kopelowicz, A., Cannon, T.D. (2006). Positive family environment predicts improvement in symptoms and social functioning among adolescents at imminent risk for onset of psychosis. Schizophr Res $\mathbf{8 1 , 2 6 9 - 2 7 5 . ~}$

Peterson, C.C., Palermo, T.M. (2004). Parental reinforcement of recurrent pain: the moderating impact of child depression and anxiety on functional disability. Pain 131:132141.

Office of Population Censuses and Surveys. Standard Occupational Classification. HMSO, London, 1990.

Rose, A.J., Rudolph, K.D. (2006). A review of sex differences in peer relationship processes: potential trade-offs for the emotional and behavioral development of girls and boys. Psychol Bull 132:98-131. 
Simons, L.E., Kaczynski, K.J. (2012). The fear avoidance model of chronic pain: examination for pediatric application. J Pain 13,827-835.

Simons, L.E., Sieberg, C.B., Claar, R.L. (2012). Anxiety and functional disability in a large sample of children and adolescents with chronic pain. Pain Res Manage 17,93-97. Steinberg, L., Morris, A.S. (2001). Adolescent developments. Annu Rev Psychol 52,83-110. Varni, J.W., Rapoff, M.A., Waldron, S.A., Bernstein, B.H., Lindsley, C.B. (1996). Chronic pain and emotional distress in children and adolescents. Dev Behav Pediatr 17,154-161. Vlaeyen, J.W.S., Linton, S. (2000). Fear-avoidance and its consequences in chronic musculoskeletal pain: a state of the art. Pain 85,317-332.

Von Korff, M., Ormel, J., Keefe, F.J., Dworkin, S.F. (1992). Grading the severity of chronic pain. Pain 50,133-49.

Walker, L.S., Sherman, A.L., Bruehl, S., Garber, J., Smith, C.A. (2012). Functional abdominal pain patient subtypes in childhood predict functional gastrointestinal disorders with chronic pain and psychiatric comorbidities in adolescence and adulthood. Pain 153,1798-1806. 


\section{Legend for illustrations and tables}

Figure 1. Overview of recruitment process

Figure 2. Percentages of reported pain locations in adolescents with recurrent pain.

Table 1 Means, $(M)$ standard deviations $(S D)$ and range statistics of pain intensity, painrelated anxiety, disability and social impairment in adolescents reporting recurrent pain $(N=$ 844; 291 boys and 553 girls).

Table 2. Percentages of the sample with recurrent pain reporting the number of days they were 'unable to perform usual activities' ( $N=844 ; 291$ boys and 553 girls).

Table 3. Hierarchical regression analysis of factors associated with adolescent level of interference, number of days unable to perform usual activities, and perceived social impairment.

Table 4. Hierarchical regression analysis of factors associated with adolescent level of interference, number of days unable to perform usual activities, and perceived social impairment for boys only $(N=291)$.

Table 5. Hierarchical regression analysis of factors associated with adolescent level of interference, number of days unable to perform usual activities, and perceived social impairment for girls only $(N=553)$. 


\section{Table 1}

Means, $(M)$ standard deviations $(S D)$ and range statistics of pain intensity, pain-related anxiety, disability and social impairment in adolescents reporting recurrent pain $(N=844 ; 291$ boys and 553 girls).

\begin{tabular}{cccc}
\hline & $\mathrm{M}$ & $\mathrm{SD}$ & range \\
\hline Pain intensity & 4.90 & 2.14 & $1-10$ \\
Male & 4.29 & 2.01 & $1-10$ \\
Female & 5.22 & 2.13 & $1-10$ \\
Pain-related anxiety & 6.13 & 5.25 & $0-27$ \\
Male & 4.39 & 4.16 & $0-19$ \\
Female & 7.04 & 5.52 & $0-27$ \\
Interference due to pain & 3.37 & 2.31 & $1-10$ \\
Male & 2.96 & 2.18 & $1-10$ \\
Female & 3.58 & 2.35 & $1-10$ \\
Social impairment & 16.96 & 6.52 & $0-41$ \\
Male & 15.60 & 6.46 & $0-41$ \\
Female & 17.68 & 6.44 & $1-36$ \\
\hline
\end{tabular}


Table 2

Percentages of the sample with recurrent pain reporting the number of days they were 'unable to perform usual activities' ( $N=844 ; 291$ boys and 553 girls).

\begin{tabular}{lcccc}
\hline & $<6$ days & 7 -14 days & $15-30$ days & $>31$ days \\
\hline Total & 81.1 & 9.4 & 4.9 & 4.6 \\
Male & 88.8 & 4.6 & 2.5 & 4.2 \\
Female & 77.1 & 11.9 & 6.2 & 4.8 \\
\hline
\end{tabular}




\section{Table 3}

Hierarchical regression analysis of factors associated with adolescent level of interference, number

of days unable to perform usual activities, and perceived social impairment.

Standardized beta coefficients from the last step in the analyses are displayed.

\begin{tabular}{|c|c|c|c|c|c|}
\hline Criterion variable & Step & Predictor & Beta & $\Delta \mathrm{R}^{2}$ & Adj. $R$ \\
\hline \multirow[t]{5}{*}{ Level of interference } & 1 & Adolescents' sex & -.037 & & \\
\hline & & Maternal social status & -.029 & & \\
\hline & & Paternal social status & -.053 & & \\
\hline & & Average intensity of pain & $.349 * * *$ & $.251 * *$ & $.246^{* *}$ \\
\hline & 2 & Pain-related anxiety & $.411 * * *$ & $.138 * * *$ & $.385^{* * *}$ \\
\hline \multirow[t]{5}{*}{$\begin{array}{l}\text { Number of days unable to perform usual } \\
\text { activities }\end{array}$} & 1 & Adolescents' sex & -.028 & & \\
\hline & & Maternal social status & .004 & & \\
\hline & & Paternal social status & .030 & & \\
\hline & & Average intensity of pain & $.193 * * *$ & $.098 * * *$ & $.092 * * *$ \\
\hline & 2 & Pain-related anxiety & $.302 * * *$ & $.075 * * *$ & $.166^{* * *}$ \\
\hline \multirow[t]{5}{*}{ Perceived pain-related social impairment } & 1 & Adolescents' sex & $.170 * * *$ & & \\
\hline & & Maternal social status & -.001 & & \\
\hline & & Paternal social status & $-.065^{\dagger}$ & & \\
\hline & & Average intensity of pain & $-.165 * * *$ & $.047 * * *$ & $.041 * * *$ \\
\hline & 2 & Pain-related anxiety & $.175^{* * *}$ & $.025 * *$ & $.065^{* *}$ \\
\hline
\end{tabular}

** $p<.01 ; * * *<.001$. Acceptable range of VIF scores (1.07-1.24). 


\section{Table 4}

Hierarchical regression analysis of factors associated with adolescent level of interference, number of days unable to perform usual activities, and perceived social impairment for boys only $(N=$ 291).

Standardized beta coefficients from the last step in the analyses are displayed.

\begin{tabular}{|c|c|c|c|c|c|}
\hline Criterion variable & Step & Predictor & Beta & $\Delta \mathrm{R}^{2}$ & Adj. $R$ \\
\hline \multirow[t]{4}{*}{ Level of interference } & 1 & Maternal social status & .077 & & \\
\hline & & Paternal social status & -.069 & & \\
\hline & & Average intensity of pain & $.328 * * *$ & $.221 * * *$ & $.210^{* * *}$ \\
\hline & 2 & Pain-related anxiety & $.357 * * *$ & $.111^{* * *}$ & $.319 * * *$ \\
\hline \multirow[t]{4}{*}{$\begin{array}{l}\text { Number of days unable to perform usual } \\
\text { activities }\end{array}$} & 1 & Maternal social status & .111 & & \\
\hline & & Paternal social status & -.023 & & \\
\hline & & Average intensity of pain & $.228 * *$ & $.116^{* * *}$ & $.104 * * *$ \\
\hline & 2 & Pain-related anxiety & $.235^{* * *}$ & $.048 * * *$ & $.148^{* * *}$ \\
\hline \multirow[t]{4}{*}{ Perceived pain-related social impairment } & 1 & Maternal social status & -.009 & & \\
\hline & & Paternal social status & $-.122^{\dagger}$ & & \\
\hline & & Average intensity of pain & -.128 & .032 & .019 \\
\hline & 2 & Pain-related anxiety & .047 & .002 & .017 \\
\hline
\end{tabular}

${ }^{\dagger} p=.08 ; * * p<.01 ; * * * p<.001$. Acceptable range of VIF scores (1.10-1.18). 


\section{Table 5}

Hierarchical regression analysis of factors associated with adolescent level of interference, number of days unable to perform usual activities, and perceived social impairment for girls only $(N=$ $553)$.

Standardized beta coefficients from the last step in the analyses are displayed.

\begin{tabular}{|c|c|c|c|c|c|}
\hline Criterion variable & Step & Predictor & Beta & $\Delta \mathrm{R}^{2}$ & Adj. $R$ \\
\hline \multirow[t]{4}{*}{ Level of interference } & 1 & Maternal social status & $-.083 *$ & & \\
\hline & & Paternal social status & -.043 & & \\
\hline & & Average intensity of pain & $.355 * * *$ & $.256 * * *$ & $.250 * * *$ \\
\hline & 2 & Pain-related anxiety & $.426^{* * *}$ & $.156^{* * *}$ & $.406^{* * *}$ \\
\hline \multirow[t]{4}{*}{$\begin{array}{l}\text { Number of days unable to perform usual } \\
\text { activities }\end{array}$} & 1 & Maternal social status & -.050 & & \\
\hline & & Paternal social status & .059 & & \\
\hline & & Average intensity of pain & $.172 * *$ & $.089 * * *$ & $.082 * * *$ \\
\hline & 2 & Pain-related anxiety & $.324 * * *$ & $.090 * * *$ & $.171^{* * *}$ \\
\hline \multirow[t]{4}{*}{ Perceived pain-related social impairment } & 1 & Maternal social status & .000 & & \\
\hline & & Paternal social status & -.037 & & \\
\hline & & Average intensity of pain & $-.180 * *$ & .011 & .004 \\
\hline & 2 & Pain-related anxiety & $.228 * * *$ & .045 & .046 \\
\hline
\end{tabular}

$* p<.05$; $^{* *} p<.01 ; * * p<.001$. Acceptable range of VIF scores (1.13-1.20). 
Click here to download high resolution image

$N=14,541$

Pregnant women enrolled in study

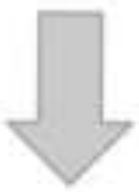

$$
N=13,988
$$

Children survived at 1 year and participated in the study

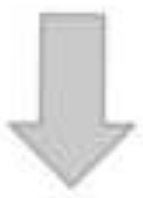

$$
N=5170
$$

Adolescents participated in the University Research Clinic

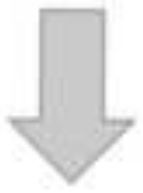

$$
N=3974
$$

Adolescents completed the pain questionnaire after attending clinic

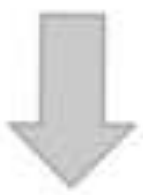

$$
N=844
$$

Adolescents reported recurrent pain 


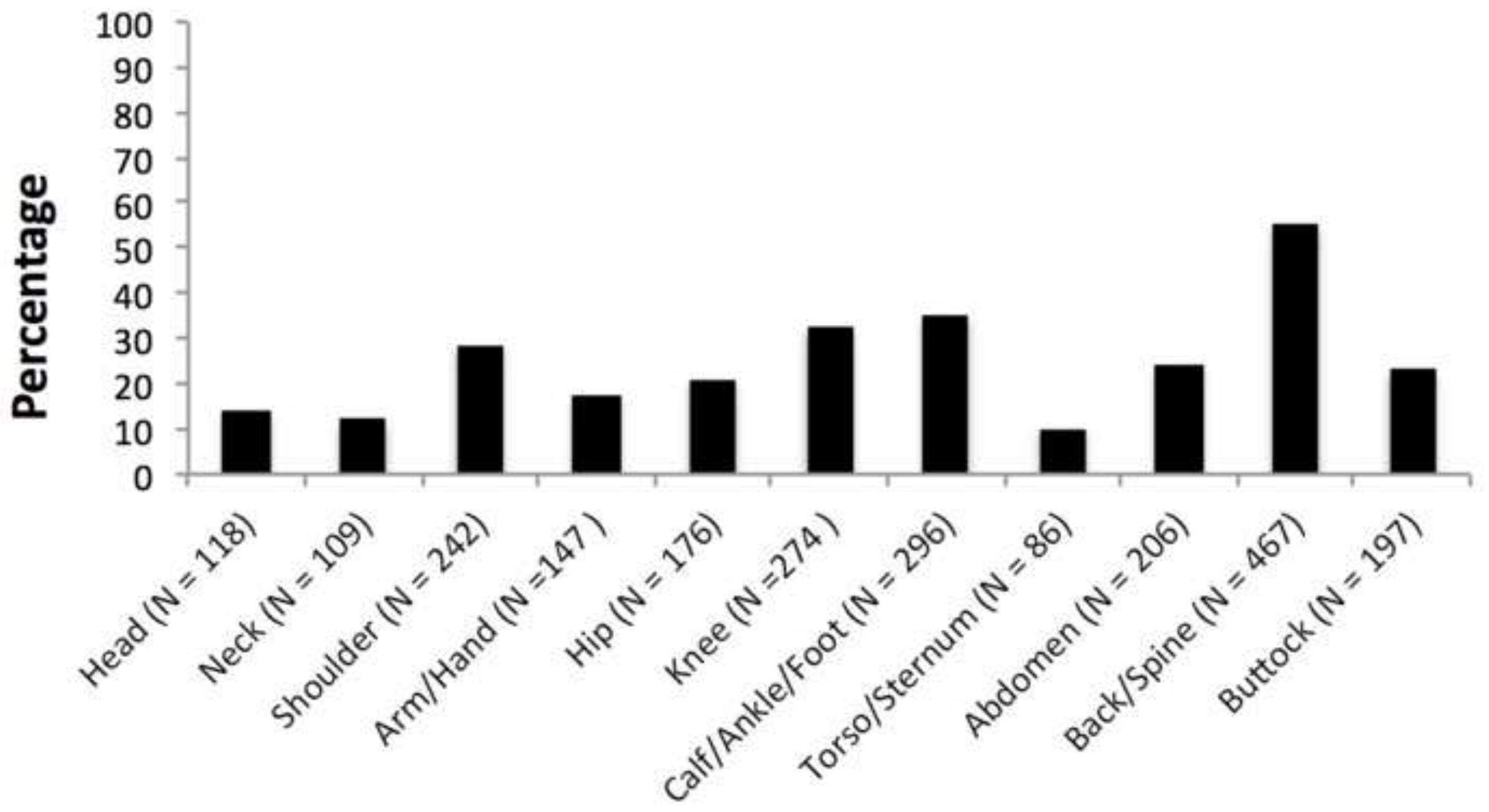

Pain location 


\section{COPYRIGHT TRANSFER AGREEMENT}

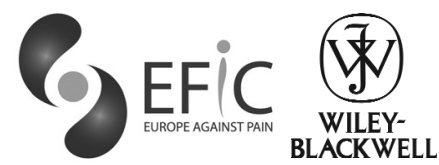
Date:
$2013 / 09 / 03$
Contributor name:
Line Caes
Contributor address:
5850/5980 University Avenue, Halifax, NS, B3K 6R8, Canada

Manuscript number (if known):

Re: Manuscript entitled

The role of pain-related anxiety in adolescents' disability and social impairment due to pain:

for publication in

EUROPEAN JOURNAL OF PAIN

(the "Journal")

published by Wiley Periodicals, Inc. or any successor publisher ("Wiley-Blackwell") on behalf of European Federation of IASP Chapters ("the Federation").

Dear Contributor(s):

Thank you for submitting your Contribution for publication. In order to expedite the editing and publishing process and enable Wiley-Blackwell on behalf of the Federation to disseminate your Contribution to the fullest extent, we need to have this Copyright Transfer Agreement signed and returned as directed in the Journal's instructions for authors as soon as possible. If the Contribution is not accepted for publication, or if the Contribution is subsequently rejected, this Agreement shall be null and void. Publication cannot proceed without a signed copy of this Agreement.

\section{A. COPYRIGHT}

1. The Contributor assigns to the Federation, during the full term of copyright and any extensions or renewals, all copyright in and to the Contribution, and all rights therein, including but not limited to the right to publish, republish, transmit, sell, distribute and otherwise use the Contribution in whole or in part in electronic and print editions of the Journal and in derivative works throughout the world, in all languages and in all media of expression now known or later developed, and to license or permit others to do so.

2. Reproduction, posting, transmission or other distribution or use of the final Contribution in whole or in part in any medium by the Contributor as permitted by this Agreement requires a citation to the Journal and an appropriate credit to the Federation and Wiley-Blackwell as Publisher, suitable in form and content as follows: (Title of Article, Contributor, Journal Title and Volume/lssue, Copyright ( $\odot$ [year], [copyright owner as specified in the Journal] [Publisher]. Links to the final article on Wiley-Blackwell's website are encouraged where appropriate.

\section{B. RETAINED RIGHTS}

Notwithstanding the above, the Contributor or, if applicable, the Contributor's Employer, retains all proprietary rights other than copyright, such as patent rights, in any process, procedure or article of manufacture described in the Contribution.

\section{PERMITTED USES BY CONTRIBUTOR}

1. Submitted Version. The Federation licenses back the following rights to the Contributor in the version of the Contribution as originally submitted for publication:

a. After publication of the final published version, the right to self-archive on the Contributor's personal website or in the Contributor's institution's/ employer's institutional repository or archive. This right extends to both intranets and the Internet. The Contributor may not update the submitted version or replace it with the published Contribution. The version posted must contain a legend as follows: This is the pre-peer-reviewed version of the following article: FULL CITE, which has been published in final form at [Link to final article].

b. The right to transmit, print and share copies with colleagues.

2. Accepted Version. Re-use of the accepted and peer-reviewed (but not final) version of the Contribution shall be by separate agreement with WileyBlackwell. Requests for permission should be addressed to the Wiley-Blackwell permissions department at Journalsrights@wiley.com. Wiley-Blackwell has agreements with certain funding agencies governing re-use of this version. The details of those relationships, and other offerings allowing open web use, are set forth at the following website: http://www.wiley.com/go/funderstatement. $\mathrm{NIH}$ grantees should check the box at the bottom of this document.
3. Final Published Version. The Federation hereby licenses back to the Contributor the following rights with respect to the final published version of the Contribution:

a. Copies for colleagues. The personal right of the Contributor only to send or transmit individual copies of the final published version in any format to colleagues upon their specific request provided no fee is charged, and further provided that there is no systematic distribution of the Contribution, e.g. posting on a listserve, website or automated delivery.

b. Re-use in other publications. The right to re-use the final Contribution or parts thereof for any publication authored or edited by the Contributor (excluding journal articles) where such re-used material constitutes less than half of the total material in such publication. In such case, any modifications should be accurately noted.

c. Teaching duties. The right to include the Contribution in teaching or training duties at the Contributor's institution/place of employment including in course packs, e-reserves, presentation at professional conferences, in-house training, or distance learning. The Contribution may not be used in seminars outside of normal teaching obligations (e.g. commercial seminars). Electronic posting of the final published version in connection with teaching/training at the Contributor's institution/place of employment is permitted subject to the implementation of reasonable access control mechanisms, such as user name and password. Posting the final published version on the open Internet is not permitted.

d. Oral presentations. The right to make oral presentations based on the Contribution.

4. Article Abstracts, Figures, Tables, Data Sets, Artwork and Selected Text (up to 250 words).

a. Contributors may re-use unmodified abstracts for any non-commercial purpose. For on-line uses of the abstracts, the Federation encourages but does not require linking back to the final published versions.

b. Contributors may re-use figures, tables, data sets, artwork, and selected text up to 250 words from their Contributions, provided the following conditions are met:

(i) Full and accurate credit must be given to the Contribution.

(ii) Modifications to the figures, tables and data must be noted. Otherwise, no changes may be made.

(iii) The re-use may not be made for direct commercial purposes, or for financial consideration to the Contributor.

(iv) Nothing herein shall permit dual publication in violation of journal ethical practices. 


\section{CONTRIBUTIONS OWNED BY EMPLOYER}

1. If the Contribution was written by the Contributor in the course of the Contributor's employment (as a "work-made-for-hire" in the course of employment), the Contribution is owned by the company/employer which must sign this Agreement (in addition to the Contributor's signature) in the space provided below. In such case, the company/employer hereby assigns to the Federation, during the full term of copyright, all copyright in and to the Contribution for the full term of copyright throughout the world as specified in paragraph A above.

2. In addition to the rights specified as retained in paragraph $B$ above and the rights granted back to the Contributor pursuant to paragraph $C$ above, the Federation hereby grants back, without charge, to such company/employer, its subsidiaries and divisions, the right to make copies of and distribute the final published Contribution internally in print format or electronically on the Company's internal network. Copies so used may not be resold or distributed externally. However, the company/employer may include information and text from the Contribution as part of an information package included with software or other products offered for sale or license or included in patent applications. Posting of the final published Contribution by the institution on a public access website may only be done with Wiley-Blackwell's written permission and payment of any applicable fee(s). Also, upon payment of Wiley-Blackwell's reprint fee, the institution may distribute print copies of the published Contribution externally.

\section{E. GOVERNMENT CONTRACTS}

In the case of a Contribution prepared under U.S. Government contract or grant, the U.S. Government may reproduce, without charge, all or portions of the Contribution and may authorize others to do so, for official U.S. Government purposes only, if the U.S. Government contract or grant so requires. (U.S. Government, U.K. Government, and other government employees: see notes at end).

\section{F. COPYRIGHT NOTICE}

The Contributor and the company/employer agree that any and all copies of the final published version of the Contribution or any part thereof distributed or posted by them in print or electronic format as permitted herein will include the notice of copyright as stipulated in the Journal and a full citation to the Journal as published by Wiley-Blackwell.

\section{G. CONTRIBUTOR'S REPRESENTATIONS}

The Contributor represents that the Contribution is the Contributor's original work, all individuals identified as Contributors actually contributed to the Contribution, and all individuals who contributed are included. If the Contribution was prepared jointly, the Contributor agrees to inform the co-Contributors of the terms of this Agreement and to obtain their signature to this Agreement or their written permission to sign on their behalf. The Contribution is submitted only to this Journal and has not been published before. (If excerpts from copyrighted works owned by third parties are included, the Contributor will obtain written permission from the copyright owners for all uses as set forth in WileyBlackwell's permissions form or in the Journal's Instructions for Contributors, and show credit to the sources in the Contribution.) The Contributor also warrants that the Contribution contains no libelous or unlawful statements, does not infringe upon the rights (including without limitation the copyright, patent or trademark rights) or the privacy of others, or contain material or instructions that might cause harm or injury.

Contributors must sign below. Contributors must check one box except that NIH grantees should check both the Contributor-owned work and the NIH grantee box. If your Contribution was written during the course of employment, your employer must also sign where indicated.

Contributor-owned work
attach Additional Signature
Pages as necessary

Co-contributor's signature

Date

Type or print name and title

Company/Institution-owned work

(made-for-hire in the

course of employment)

Company or Institution (Employer-for-Hire)

Date

Authorized signature of Employer

Date

U.S. Government work

Note to U.S. Government Employees

A contribution prepared by a U.S. federal government employee as part of the employee's official duties, or which is an official U.S. Government publication, is called a "U.S. Government work," and is in the public domain in the United States. In such case, the employee may cross out Paragraph A.1 but must sign (in the Contributor's signature line) and return this Agreement. If the Contribution was not prepared as part of the employee's duties or is not an official U.S. Government publication, it is not a U.S. Government work.

U.K. Government work
(Crown Copyright)

\section{Note to U.K. Government Employees}

The rights in a Contribution prepared by an employee of a U.K. government department, agency or other Crown body as part of his/her official duties, or which is an official government publication, belong to the Crown. U.K. government authors should submit a signed declaration form together with this Agreement. The form can be obtained via http://www.opsi.gov.uk/advice/crown-copyright/copyright-guidance/ publication-of-articles-written-by-ministers-and-civil-servants.htm
Other Government work

\section{Note to Non-U.S., Non-U.K. Government Employees}

If your status as a government employee legally prevents you from signing this Agreement, please contact the editorial office.
NIH Grantees

\section{Note to NIH Grantees}

Pursuant to $\mathrm{NIH}$ mandate, Wiley-Blackwell will post the accepted version of Contributions authored by $\mathrm{NIH}$ grant-holders to PubMed Central upon acceptance. This accepted version will be made publicly available 12 months after publication. For further information, see www.wiley.com/go/nihmandate. 